\title{
Genetic diversity and virulence of Colletotrichum Iupini isolates collected in Chile
}

\author{
Ricardo Riegel ${ }^{1}$, Débora Véliz ${ }^{1}$, Ingrid von Baer ${ }^{2}$, Yerko Quitral $^{1}$ \& Manuel Muñoz ${ }^{1}$ \\ ${ }^{1}$ Graduate School, Faculty of Agricultural Sciences, Universidad Austral de Chile, Valdivia, Chile; ${ }^{2}$ Seeds von Baer, Temuco, \\ Chile
}

Author for correspondence: Ricardo Riegel, e-mail: rriegel@uach.cl

\begin{abstract}
All nineteen Colletotrichum isolates causing anthracnose in lupin plants growing in southern Chile belong to Colletotrichum lupini, confirming an absence of interspecific variation in the causal agent of anthracnose. Nevertheless, intraspecific genetic diversity was detected with random amplified polymorphic DNA (RAPD) markers. Based on a multiloci analysis, 14 molecular phenotypes were described among the local $C$. lupini isolates. The largest genetic distance between two isolates was 0.57 . The analyzed isolates showed clear differences in virulence on susceptible cultivar 'Kiev Mutant' with disease severity ranging from 15 to $75 \%$ of seedlings. The high degree of DNA polymorphism, the large number of different molecular phenotypes, and the variation in virulence suggest the existence of different strains. Study of strain virulence and diversity may aid in the development of more efficient genetic improvement programs for anthracnose tolerance.
\end{abstract}

Keywords: Lupinus, anthracnose.

\section{INTRODUCTION}

The further expansion of lupin (Lupinus spp.) cultivation depends on the development of cultivars that tolerate anthracnose, the most important and devastating disease in this crop (Cowling et al., 1998). This fungal disease was first described in 1939 in Lupinus angustifolius of North America, with the causal agent being identified as Glomerella cingulata (anamorph Colletotrichum gloeosporioides) (Weimer, 1943). By the end of the 1970s, anthracnose was described on lupins in Europe, and by the end of the 1980s, on lupins in New Zealand. In 1994, it was detected in Western Australia (Sweetingham et al., 1995). Using traditional taxonomy, the anthracnose affecting $L$. angustifolius in Chile was officially described in 1988 as $C$. gloeosporioides (Peredo \& Valenzuela, 1988). The taxonomy of Colletotrichum, which causes anthracnose in lupins, has been debated over the last few years. Some authors have described $C$. gloeosporioides as the phytopathogen of this disease, while others argue for C. acutatum or an entirely different Colletotrichum species. Nirenberg et al. (2002) re-described the pathogen causing lupin anthracnose as C. lupini. Nevertheless, in recent work, Sreenivasaprasad \& Talhinhas (2005) argued to keep the classification as $C$. acutatum and suggested a division of the currently described different populations into groups. The isolates classified as C. lupini by Nirenberg et al. (2002) and the majority of the worldwide isolates of lupin anthracnose fit within the highly homogeneous group A1 from C. acutatum that was described by Sreenivasaprasad \& Talhinhas (2005). After the description given by Nirenberg et al. (2002), C. lupini is now accepted as the causal agent of anthracnose in lupins (Lotter \& Berger 2005; Tivoli et al., 2006; Thomas et al., 2008; Yang et al., 2008).

Traditionally, Colletotrichum species have been identified by morphological characteristics such as conidial and apressorium shape, presence or absence of setae, and growth rate, and also pathogenicity and biochemistry (Gunnell \& Gubler, 1992; Muñoz et al. 2000; Nirenberg et al., 2002). Classification by this method requires considerable experience and technical ability but especially so for a complex species like Colletotrichum, which has morphological variants that infect diverse hosts (Adaskaveg \& Hartin, 1997; Yang \& Sweetingham, 1998; Sreenivasaprasad \& Talhinhas, 2005). Recently, the conventional biological concept of species in eukaryotes has been discussed and re-analyzed, and methods of classification are constantly being modified to incorporate new ways of obtaining information (Martínez-Culebras et al., 2000). At present, molecular techniques have a crucial role in contributing to classification and, in some cases, the re-defining of taxa. The ribosomal DNA sequences encoding the 5.8S rRNA and the two internal transcribed spacers ITS1 and ITS2 have greatly aided in molecular identification of some Colletotrichum species causing anthracnose in diverse crops (Adaskaveg \& Harting, 1997; Martínez-Culebras et al., 2000; Abang et al., 2002; Sreenivasaprasad \& Talhinhas, 2005). A technique known as ITS-RFLP is often used for 
rapid molecular identification of species. Specific fragments of ribosomal DNA are amplified by PCR and analyzed by restriction enzyme digest. This technique has not yet been used to differentiate Colletotrichum species causing lupin anthracnose.

In general, ribosomal genes and spacers remain highly conserved within species; therefore it cannot be used to assess intraspecific genetic diversity. In contrast, random amplified polymorphic DNA (RAPD) markers (Williams et al., 1990) have been successfully used to analyze the diversity of isolates belonging to a variety of Colletotrichum species (Kelemu et al., 1999; Martinez-Culebras et al. 2002; Afanador-Kafuri et al., 2003). For the causal agent of anthracnose in lupins, RAPD analysis was carried out mainly to support the assignment of the pathogen into a specific species and subspecies. A wide range of isolates of varying geographical origin have been analyzed (Yang \& Sweetingham, 1998; Nirenberg et al., 2002) but the genetic diversity of the anamorph of this phytopathogen in a reduced distribution area is not known. The objective of this study was to determine if there were differences in virulence and inter- and/or intraspecific genetic diversity in fungal isolates causing anthracnose in lupins in a small geographic area of Chile. To determine the interspecific differentiation between C. lupini, C. gloeosporioides, and C. acutatum, it was necessary to develop a reliable and easy molecular method.

\section{MATERIAL AND METHODS}

\section{Fungal isolates}

Nineteen isolates of Colletotrichum spp. were obtained from leaves, pods, or stems of different lupin species affected by anthracnose. Isolates were collected in different regions of southern Chile (Table 1), within a northsouth transect of $120 \mathrm{Km}$. Fungal isolates were cultured initially on a solid medium of potato-dextrose-agar (PDA) from which monosporic cultures were obtained. To validate analyses, four reference strains were used belonging to Colletotrichum gloeosporioides, C. acutatum, C. lupini var. lupini and $C$. lupini var. setosum. These strains were provided by the Federal Biological Research Center for Agriculture and Forestry, Berlin, Germany.

\section{DNA extraction}

The mycelial growth was re-activated and incubated in $25 \mathrm{ml}$ of liquid potato-dextrose media (CPD; $200 \mathrm{~g}$ of peeled potato with $12.5 \mathrm{~g}$ glucose per liter of solution) at

TABLE 1 - Source of Colletotrichum spp. isolates

\begin{tabular}{|c|c|c|c|c|}
\hline Isolate & Location/Country & Hos & & Species \\
\hline A-1 & Gorbea / Chile & L. albus & accession (sweet) & C. lupini \\
\hline A-2 & Cajón / Chile & L. albus & cultivar TypTop (sweet) & C. lupini \\
\hline A-3 & Cajón / Chile & L. albus & accession (sweet) & C. lupini \\
\hline A- 4 & Cajón / Chile & L. angustifolius & accession (sweet) & C. lupini \\
\hline A-5 & Traiguen / Chile & L. albus & cultivar Rumbo (sweet) & C. lupini \\
\hline A- 6 & Temuco / Chile & L. albus & cultivar Rumbo (sweet) & C. lupini \\
\hline A-7 & Boroa / Chile & L. albus & accession (bitter) & C. lupini \\
\hline A- 8 & Boroa / Chile & L. albus & accession (bitter) & C. lupini \\
\hline A-9 & Boroa / Chile & L. albus & cultivar Perla (sweet) & C. lupini \\
\hline A- 10 & Cajón / Chile & L. angustifolius & cultivar Ruso (sweet) & C. lupini \\
\hline A-11 & Cajón / Chile & L. angustifolius & accession (sweet) & C. lupini \\
\hline A- 13 & Perquenco / Chile & L. albus & cultivar Rumbo (sweet) & C. lupini \\
\hline A-14 & Cajón / Chile & L. polyphyllus & accession (bitter) & C. lupini \\
\hline A- 15 & Victoria / Chile & L. angustifolius & accession (bitter) & C. lupini \\
\hline A- 16 & Victoria / Chile & L. albus & - & C. lupini \\
\hline A-17 & Allipen / Chile & L. albus & cultivar Rumbo (sweet) & C. lupini \\
\hline A-19 & Lautaro / Chile & L. albus & accession (bitter) & C. lupini \\
\hline P-1 & Gorbea / Chile & L. albus & - & C. lupini \\
\hline $\mathrm{V}-2$ & Vilcún / Chile & L. albus & - & C. lupini \\
\hline BBA70071 ${ }^{1}$ & - / Thailand & Citrus & - & C. gloeosporioides \\
\hline BBA71292 ${ }^{1}$ & - / Portugal & L. albus & - & C. acutatum \\
\hline BBA $63879^{1}$ & - / Bolivia & L. mutabilis & - & C. lupini var. lupini \\
\hline BBA70358 ${ }^{1}$ & - / Germany & L. albus & - & C. lupini var. setosum \\
\hline
\end{tabular}

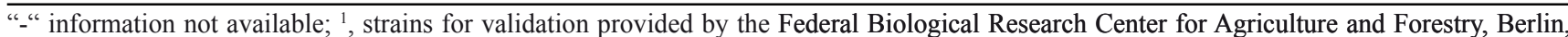
Germany and cited by Nirenberg et al. (2002). 
$22 \pm 2^{\circ} \mathrm{C}$ for seven days in the dark while stirring at $150 \mathrm{rpm}$ (Kuramae-Izioka et al., 1997). Total genomic DNA was isolated from the mycelia using the method described by Goodwin et al. (1992). Isolated DNA was purified using $5 \mu \mathrm{L}$ RNase A $(10 \mathrm{mg} / \mathrm{mL})$; the DNA concentration was measured by spectrometry, and dilutions were made to a final concentration of $30 \mathrm{ng} / \mu \mathrm{L}$.

\section{ITS-RFLP assays and sequencing}

To identify the species of Colletotrichum for each collected isolate, we performed the ITS-RFLP molecular technique. To detect point mutations, which allows species level distinction, the sequences of two internal transcribed spacers (ITS1 and ITS2) were aligned from 21 strains of different Colletotrichum species. These sequences were AJ301908 and AJ301986 of C. gloeosporioides; AJ301911, AJ301915, AJ301920, AJ301921, AJ301922, AJ301950, and AJ301964 of C. acutatum; and AJ301916, AJ301918, AJ301923, AJ301927, AJ301928, AJ301930, AJ301933, AJ301934, AJ301935, AJ301948, AJ301959, and AJ301968 of C. lupini; (Nirenberg et al., 2002). After identifying occasional intraspecific mutations, specific restriction enzymes were selected that could recognize these sites.

For the isolates used in this study, the ITS1 and ITS2 regions were amplified by PCR using the universal primers ITS5+ITS2 and ITS3+ITS4, respectively (White et al., 1990). All PCR experiments were performed in a total volume of $25 \mu \mathrm{L}$, containing $30 \mathrm{ng}$ of DNA, 1X PCR buffer (20 mm Tris- $\mathrm{HCl}$ at $\mathrm{pH} 8.4,50 \mathrm{~mm} \mathrm{KCl}$ ), $2.4 \mathrm{~mm}$ of $\mathrm{MgCl}_{2}, 2$ mM of each dNTP, $0.5 \mathrm{U}$ Taq DNA polymerase (Invitrogen, USA), and $0.4 \mu \mathrm{M}$ of each universal primer (MWG Biotech, Ebersberg, Germany). The reaction mixture was incubated in a PTC-100 thermocycler (M.J. Research Inc., MA, USA) programmed for $3 \mathrm{~min}$ at $94^{\circ} \mathrm{C}$ for initial denaturation, followed by 39 cycles of denaturation at $94^{\circ} \mathrm{C}$ for $30 \mathrm{~s}$, annealing at $59^{\circ} \mathrm{C}$ for $1 \mathrm{~min}$, extension at $72^{\circ} \mathrm{C}$ for $1 \mathrm{~min}$, and a final extension at $72^{\circ} \mathrm{C}$ for $5 \mathrm{~min}$.

The expected size of the fragments ranged from 275 to $285 \mathrm{bp}$ for the ITS1 region and 346 to $347 \mathrm{bp}$ for the ITS2 region. Digestion of PCR products with the selected restriction enzymes was performed in a total volume of 20 $\mu 1: 10 \mu \mathrm{L}$ of PCR product, $4.0 \mu \mathrm{L}$ of enzyme-specific buffer, $0.5 \mu \mathrm{L}$ of enzyme $(10 \mathrm{U} / \mu \mathrm{L}$, Fermentas $\mathrm{GmbH}$, St LeonRot, Germany), and $5.5 \mu \mathrm{L}$ of sterile deionized water. The sample was incubated for 4 hours at $37^{\circ} \mathrm{C}$ or $65^{\circ} \mathrm{C}$, depending on the enzyme. PCR products of the amplified ITS regions and the fragments obtained from the enzymatic digest were separated on 1-1.5\% agarose gels. After electrophoresis, gels were stained with ethidium bromide, and the DNA bands were visualized and photographed under UV light. The presence or absence of the species-specific banding patterns after enzymatic restriction was analyzed. For all isolates collected in Chile, PCR amplification of the ITS region was achieved using the universal primers ITS5 and ITS4, as described above. PCR products were purified, and both strands were sequenced directly (Macrogen Inc).

\section{RAPD assays}

In preliminary experiments, a total of 20 primers were screened with two isolates of Colletotrichum. The name and source of the primers were: OPA-09, OPA-10, OPA-16, OPA 17, OPB-01, OPB-06, OPB-08, OPD-05, OPD-09, OPE-01, OPE-06, OPE-08, OPE-09, OPE-11, OPE-20, ORF-07, ORF-08, ORF-09, from the OperonTechnologies series, PSM-No 72 and PSM-No 86 from Nirenberg et al. (2002). The only primers used to analyze all strains were those that yielded high reproducibility, sharp bands, and at least one polymorphic locus.

The RAPD-PCR reactions were performed in a final volume of $25 \mu \mathrm{l}$, containing $30 \mathrm{ng}$ of DNA, 1X PCR buffer (20 mM Tris- $\mathrm{HCl}$ at $\mathrm{pH} 8.4,50 \mathrm{~mm} \mathrm{KCl}$ ), $4 \mathrm{~mm}$ of $\mathrm{MgCl}_{2}, 2$ mM of each dNTP, 0.5 U Taq DNA polymerase (Invitrogen) and $0.4 \mu \mathrm{M}$ primer (MWG Biotech). Amplification was carried out in a thermocycler PTC-100 with temperature profiles of $94^{\circ} \mathrm{C}$ for $3 \mathrm{~min}$, followed by 40 cycles at $94^{\circ} \mathrm{C}$ for $45 \mathrm{~s}, 35^{\circ} \mathrm{C}$ for $45 \mathrm{~s}, 72^{\circ} \mathrm{C}$ for $1.5 \mathrm{~min}$, and one final cycle at $72^{\circ} \mathrm{C}$ for $5 \mathrm{~min}$. The PCR profiles were resolved by electrophoresis using $2 \%$ agarose gels at $50 \mathrm{~V}$ for 3 to 4 hours. The same methodology that was described for the ITS-RFLP technique was used for analysis.

DNA fingerprints generated by RAPD for every Colletotrichum isolate were scored for the presence "1" or absence " 0 " of bands of particular sizes. Positional homology of amplified fragments was assumed, and only polymorphic bands were considered in the final analyses. The resulting binary matrix was used as the basis for determining Nei's (1973) genetic diversity (POPGENE ver. 1.31; Yeh and Boyle, 1999) and genetic distance, according to Nei and Li (1979) (WINBOOT; Yap and Nelson, 1996). Dissimilarity coefficients were clustered to generate a tree using the unweighted pair-group method with arithmetic average (UPGMA) algorithm in PHYLIP (Felsenstein, 1989). The confidence limits of the groups produced by the dendrograms were evaluated using a bootstrap analysis of 1000 replications (WINBOOT; Yap \& Nelson, 1996).

\section{Virulence analysis}

Based on the genetic distance obtained with RAPD markers, nine representative isolates of $C$. lupini collected in Chile were chosen for a virulence assay. Inoculation, which simulates a primary infection, was performed according to Feiler \& Nirenberg (2004). In brief, to each liter of a peatstraw-sand (3:1:1) mixture, $2.7 \mathrm{~g}$ of lime, $7 \mathrm{~g}$ of malt extract, and 10 pieces of $1 \mathrm{~cm}^{2}$ of PDA media with mycelium were added. After the mycelium colonized the entire substrate (approx. three days at room temperature), it was mixed with soil at a ratio of 1:2 and transferred to 1.5 liter pots.

The experiment was conducted in a completely randomized block design with 27 treatments, consisting of three white lupin (L. albus) genotypes (susceptible cv. 'Kiev Mutant' (Feiler \& Nirenberg, 2004), tolerant cv. 'Pecosa-Baer' (von Baer et al., 2009) and '246-9' (tolerance unknown) inoculated with nine isolates (A-1, A-2, A-4, A-5, 
A-6, A-7, A-10, A-14, A-15). Four replications per treatment were conducted. Each replication consisted of one pot and five seeds per pot. Additionally, for each genotype a control without inoculation was performed.

Pots containing the inoculated substrate and seeds were kept in a greenhouse at a day temperature that ranged between 20 and $25^{\circ} \mathrm{C}$ and an average humidity of $65 \%$. Plants were rated at three weeks after inoculation based on presence or absence of symptoms like cotyledon lesions, necrosis or bending of the hypocotyl (Feiler \& Nirenberg, 2004). The percentage of affected plants in each pot was transformed to arccosine (Zar, 1999) for doing a factorial ANOVA, considering lupin genotypes and fungus isolation as fixed factors. The Tukey HSD test was performed in cases of significance. Since genotypes $\mathrm{x}$ isolate interaction was not significant, one-way ANOVA was performed for analyzing the effects of isolation on survival of each variety separately.

\section{RESULTS}

\section{Interspecific diversity}

It was possible to detect species-specific point mutations based on alignment of ITS1 and ITS2 sequences with currently available databases of different strains belonging to C. gloeosporioides, C. acutatum and C. lupini. Two of these mutations were adequate for the development of an ITS-RFLP assay. Within the ITS1 region, a Bsh $1236 I$ restriction site is only present in the strains of $C$. acutatum and C. lupini and absent from C. gloeosporioides (Table 2). Accordingly, the ITS1 fragments from $C$. acutatum and $C$. lupini were cut by this enzyme, producing two fragments of 125 and $160 \mathrm{bp}$, whereas the fragment from C. gloeosporioides remained uncut with $275 \mathrm{bp}$. In the ITS2 region, the enzyme Tru $I I$ has two sites in $C$. acutatum and only one in C. gloeosporioides and C. lupini. As a result, the digest of ITS2 fragments created three fragments (23, 141 , and $182 \mathrm{bp}$ ) in the C. acutatum strain and only two fragments in C. gloeosporioides and C. lupini (23 and $321 \mathrm{bp}$ ). Together, the analysis of restriction profiles of both ITS1 and ITS2 regions enabled a clear identification of the three studied species of Colletotrichum. This result was confirmed by the validation strains and is presented in Figure 1. The described ITS-RFLP technique was applied to the 19 Colletotrichum isolates collected from lupins in Chile. In all cases, the characteristic fragment profile of $\mathrm{C}$. lupini was detected (Figure 1) and confirmed by sequencing. For all local isolates, the same ITS region sequence was obtained (DNA sequence accession EU589451), which was identical to C. lupini var. setosum described by Nirenberg et al. (2002).

\section{Intraspecific diversity}

Of the 20 screened RAPD primers, five were selected (OPA-10, OPD-05, OPE-20, PSM-No 72 (Figure 2), PSM-No 86) for further analysis of all Colletotrichum isolates. Each reaction was performed at least twice, and good reproducibility of banding patterns was obtained. The five primers produced 48 polymorphic bands. On average, 9.6 fragments were scored per primer, with a range of 7 (OPD 05) to 15 fragments (PSM-No 86) per primer.

In the 19 local isolates analyzed, 14 molecular phenotypes (haplotypes) were detected, of which 12 occurred only once. The most frequent molecular phenotype was shared by the isolates V-2, A-8, A-10, A-11, and A-13. These different isolates, with the same RAPD banding patterns, were obtained in different localities from L. angustifolius and L. albus (sweet and bitter). Only the isolates A-10 and A-11 were from the same location and host species. The isolate V-2 was collected three years earlier than the rest of the isolates of the same haplotype. Isolates A-7 and A-9, which had a similar origin, also presented the same molecular phenotype.

The mean genetic diversity in the Chilean haplotypes of $C$. lupini was 0.24 . The greatest genetic distance, 0.57 , was observed between A-3 and A-5, which were taken from Cajón and Traiguén, respectively, from hosts of different $L$. albus genotypes. The highest genetic distance $(0.53)$ between two isolates from the same genotype of $L$. albus (cultivar Rumbo) was found between isolates A-5 and A-

TABLE 2 - Partial sequences of the rDNA internal transcribed spacer ITS1 and ITS2 of C. gloeosporioides, C. acutatum, and C. lupini. The underlined sequence corresponds to the species-specific restriction sites of the endonucleases Bsh $1236 I$ (CG $\downarrow$ CG) and Tru 1 (I (T $\downarrow$ TAA). The combination of both enzymes was used to differentiate Colletotrichum species with the ITS-RFLP assay

\begin{tabular}{|c|c|c|c|c|c|}
\hline Species & $\begin{array}{l}\text { Sequence in the ITS1 } \\
\text { region }\end{array}$ & $\begin{array}{l}\text { Cut with } \\
\text { Bsh 1236I }\end{array}$ & $\begin{array}{c}\text { Sequence in the ITS2 } \\
\text { region }\end{array}$ & $\begin{array}{c}\text { Cut with } \\
\text { Tru 1I }\end{array}$ & Isolate \\
\hline C. gloeosporioides & $\begin{array}{c}. . \text { TCTCCGTGACCC .. } \\
. .\end{array}$ & - & $\begin{array}{c}. . \text { GCCCTCAAAGGT.. } \\
. .\end{array}$ & - & BBA70071 \\
\hline C. acutatum & ..CTCTCGCGGGCC.. & + &..$G C C C \frac{\text { TTAA AGGT.. }}{. .}$ & + & BBA71292 \\
\hline C. lupini & ..CTCTCGCGGGCC.. & + & ..GCCCTTGAAGGT.. & - & $\begin{array}{c}\text { BBA70358; BA63879; A-1; A- } \\
\text { 2; A-3; A-4; A-5; A-6; A-7; A- } \\
\text { 8; A-9; A-10; A-11; A-13; A- } \\
\text { 14; A-15; A-16; A-17; A-19; P- } \\
\text { 1; V-2 }\end{array}$ \\
\hline
\end{tabular}



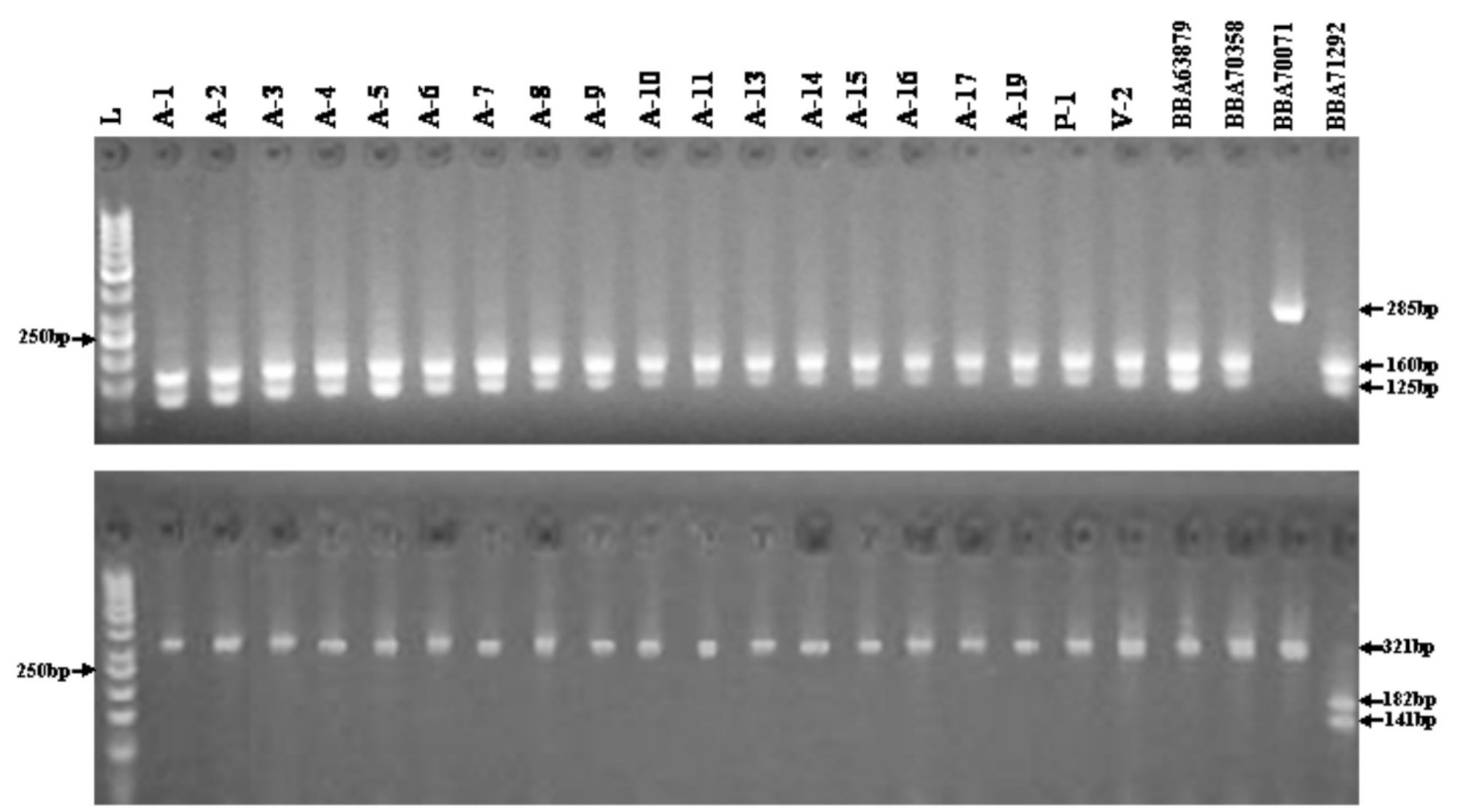

FIGURE 1 - DNA fragment patterns of the internal transcribed spacer ITS1 digested with the endonuclease Bsh 1236I (top) and the ITS2 region digested with the enzyme Tru 1I (bottom). Isolates in lanes 2-20 belong to C. lupini collected in Chile (Table 1). Lanes 21-24 correspond to the reference strains C. lupini var. lupini (BBA63879), C. lupini var. setosum (BBA70358), C. gloeosporioides (BBA70071), and C. acutatum (BBA71292). L: 50 bp ladder used as molecular size standard. Arrows show the length of expected fragments.

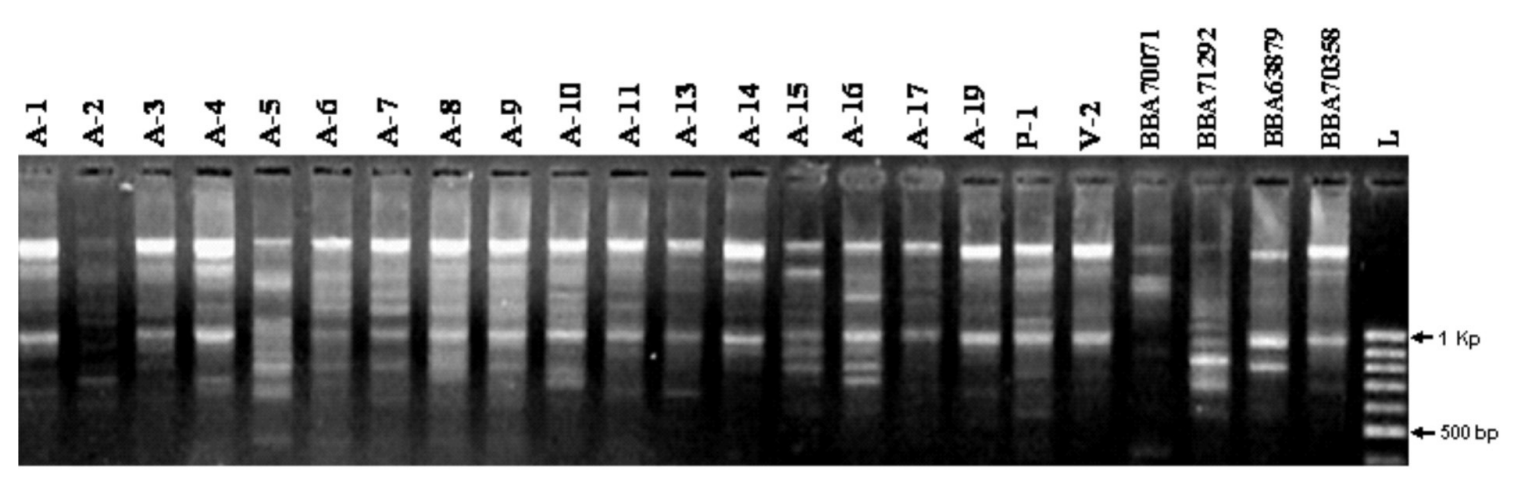

FIGURE 2 - Randomly amplified polymorphic DNA (RAPD) patterns of 23 isolates using primers PSM-No 72. Isolates in lanes 1-19 belong to $C$. lupini collected in Chile. Lanes 20-23 correspond to the validation strains C. gloeosporioides (BBA70071), C. acutatum (BBA71292), C. lupini var. lupini (BBA63879), and C. lupini var. setosum (BBA70358) (Table 1). L: 100 bp ladder used as molecular size standard.

13. The isolates A-2 and A-3 presented the greatest genetic distance among isolates obtained from the same region (0.4).

The genetic distances, based on all polymorphic RAPD fragments, were used to group isolates by the UPGMA method. The genetic relationship between isolates is presented in the form of a dendrogram in Figure 3. As with the ITS-RFLP technique, the data obtained from RAPDs markers clearly differentiated the three species $C$. acutatum, C. gloeosporioides, and C. lupini. The cluster analysis resolved the species into different groups, which was supported by high bootstrap values.
In the dendrogram, the isolates of $C$. lupini formed different groups that do not coincide with the existing classification of the special forms of $C$. lupini var. lupini and $C$. lupini var. setosum. The two reference strains of C. lupini separated into a different genetic group than the local isolates. Seventeen of the nineteen local isolates fell within one major cluster (Figure 3). Isolates A-2 and A-5 fell outside of this major cluster, forming different groups supported by high bootstrap values. Considering only the local isolates and setting aside the reference strains (BBA 70358 and BBA 63879), the definition of the major cluster was supported by a bootstrap of $88 \%$ (data not shown). 


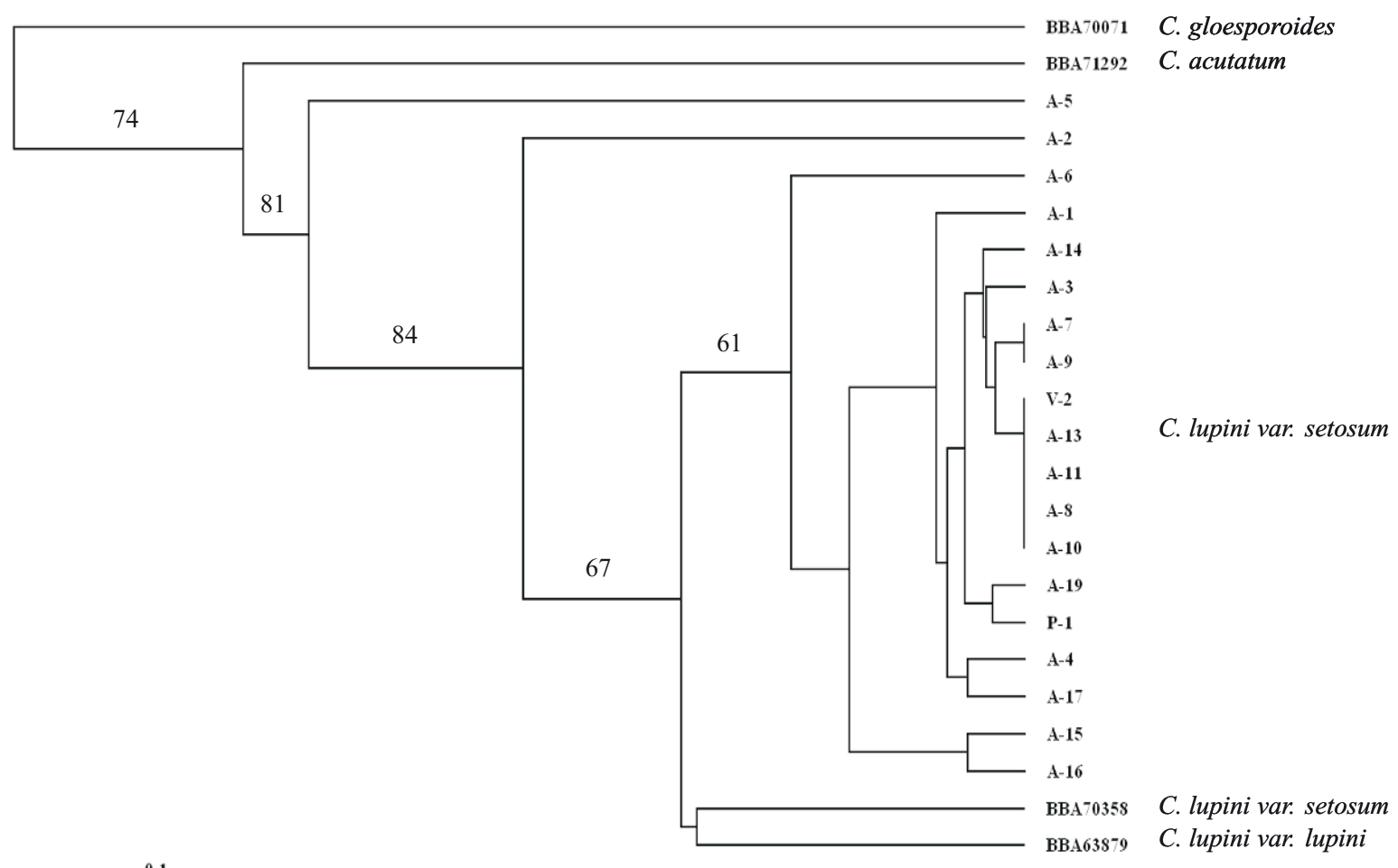

FIGURE 3 - Dendrogram based on UPGMA analysis of the genetic distances resulting from the evaluation of 48 polymorphic RAPD fragments in 23 Colletotrichum isolates. Details of isolate, host and place of collection are given in Table 1 . Bootstrap values over $60 \%$ are given above the principal branches.

Within this cluster were isolates obtained from different hosts and diverse localities.

\section{Virulence analysis}

The pathogenicity of all isolates was confirmed. Characteristic symptoms of anthracnose were easy to score on diseased plants. The severity of the disease was variable and dependent on the isolate and the lupin genotype (Table $3)$. No significant interaction was found between the nine isolates and the three lupin genotypes tested. On average, the less virulent isolates A-1, A-2, and A-6 caused symptoms in less then $13 \%$ of the plants; however, the highly virulent isolates A-10, A-14, and A-15 visibly affected more than $45 \%$ of the seedlings. The highest difference in virulence could be detected in the cultivar 'Kiev Mutant' between isolates A-2 with $15 \%$ and A-10 with $75 \%$ infection. As expected from previous reports (Feiler \& Nirenberg, 2004; von Baer et al., 2009), the cultivar 'Pecosa-Baer' was more tolerant than 'Kiev Mutant'.

\section{DISCUSSION}

Adaskaveg \& Harting (1997) developed specific ITS-PCR primers for differentiating C. gloeosporioides from $C$. acutatum at the molecular level and demonstrated their effectiveness on different anthracnose strains isolated from strawberry, almond, peach, and papaya. Yang \& Sweetingham (1998) used the same method for strains of lupin anthracnose, and while it identified the strains as $C$. acutatum, they preferred traditional taxonomy and instead characterized the strains as $C$. gloeosporioides by morphology. In contrast, Talhinhas et al. (2002) argued that most morphologic characteristics, with the exception of spore morphology and mycelium growth speed, are not adequate for differentiating C. gloeosporioides from C. acutatum. Using these morphological parameters and molecular data, Talhinhas et al. (2002) and Sreenivasaprasad \& Talhinhas (2005) determined that most of the analyzed lupin anthracnose isolates from around the world belonged to a homogeneous group within $C$. acutatum. Nirenberg et al. (2002) attempted to resolve the big discussion and confusion that arose around the classification of this phytopathogen by redefining the causal agent of the anthracnose in lupins as a new species, $C$. lupini, based on morphologic and molecular parameters. Considering the partial host specificity, homogeneity within conserved DNA sequences, and differentiation from other C. acutatum groups, we adopted the nomenclature used by Nirenberg et al. (2002).

Since C. lupini shares more molecular similarity with $C$. acutatum than with $C$. gloeosporioides, we inferred that the species-specific primers developed by Adaskaveg 
TABLE 3 - Virulence analysis of Colletotrichum lupini isolates on different white lupin (Lupinus albus) genotypes

\begin{tabular}{|c|c|c|c|c|}
\hline \multirow[t]{2}{*}{ Isolates } & \multicolumn{4}{|c|}{ Lupin genotypes } \\
\hline & cv. 'Kiev Mutant' & cv. 'Pecosa-Baer' & Line '246-9' & Average \\
\hline A-1 & $20 \mathrm{a}^{1}$ & $0 \mathrm{a}$ & $15 \mathrm{ab}$ & $12 \mathrm{a}$ \\
\hline A-2 & $15 \mathrm{a}$ & $5 \mathrm{a}$ & $5 \mathrm{a}$ & $8 \mathrm{a}$ \\
\hline A-4 & $45 \mathrm{abc}$ & $15 a b c$ & $20 \mathrm{abc}$ & $27 \mathrm{ab}$ \\
\hline A-5 & $55 \mathrm{abc}$ & $30 \mathrm{bc}$ & $35 \mathrm{bcd}$ & $40 \mathrm{~b}$ \\
\hline A-6 & $30 a b$ & $0 \mathrm{a}$ & $10 \mathrm{ab}$ & $13 \mathrm{a}$ \\
\hline A-7 & $55 \mathrm{abc}$ & $35 \mathrm{c}$ & $35 \mathrm{bcd}$ & $42 \mathrm{~b}$ \\
\hline A-10 & $75 \mathrm{c}$ & $10 \mathrm{ab}$ & $55 \quad \mathrm{~d}$ & $45 \mathrm{~b}$ \\
\hline A-14 & $70 \mathrm{bc}$ & $20 a b c$ & $45 \mathrm{~cd}$ & $47 \mathrm{~b}$ \\
\hline A-15 & $60 \mathrm{bc}$ & $30 \mathrm{bc}$ & $60 \quad \mathrm{~d}$ & $50 \mathrm{~b}$ \\
\hline Average & $47 \mathrm{~A}$ & $16 \mathrm{C}$ & $31 \mathrm{~B}$ & \\
\hline
\end{tabular}

'Percentage of seedlings with symptoms of anthracnose infection (cotyledon lesions, necrosis or bending of the hypocotyl). Values followed by the same lower case letter within a column and upper case letters in the average row are not significantly different at $\mathrm{P}<0.05$ according to Tukey's test.

\& Harting (1997) and later used by Yang \& Sweetingham (1998) and Talhinhas et al. (2002) could discriminate between C. gloeosporioides and C. lupini but not C. lupini and $C$. acutatum. With the ITS-RFLP assay developed in our study, this problem was resolved. The amplification of rDNA segments (ITS1 and ITS2) and their restriction with the enzymes Bsh $1236 I$ and Tru $1 I$ allowed a rapid and unmistakable identification of the three species under discussion. Although the ITS-RFLP technique is more labor-intensive than the use of species-specific primers, it is more robust and reproducible, since there is no need for primer optimization.

In Chile, the main areas of lupin cultivation were sampled, and only $C$. lupini was detected as the causal agent of anthracnose. The absence of interspecific diversity is in accordance with most of the previously published worldwide studies (Yang \& Sweetingham, 1998; Talinhas et al., 2002). In the Azores, C. lupini and C. acutatum were found in lupins; however, it was suggested that $C$. acutatum colonization on lupin was a saprophytic colonization that would occur only occasionally (Nirenberg et al., 2002). As in Nirenberg et al. (2002), the multiloci analysis of RAPD data clearly distinguished between $C$. lupini, C. acutatum, and C. gloeosporioides. Even the C. lupini isolate A5 , which presents the lowest genetic distance from $C$. acutatum, differs in $48 \%$ of the evaluated RAPD bands.

Yang \& Sweetingham (1998) analyzed different isolates of Colletotrichum obtained from infected lupins with 11 RAPDs primers. They obtained three clearly differentiable groups that coincided with the vegetative compatibility group classification (VCG). The most important group, COL-2, later classified by Nirenberg et al. (2002) as C. lupini var. setosum, had isolates from all over the world; these isolates, however, were very homogeneous and possessed no molecular inter-isolate variation. The presence of only one haplotype within the group COL-2 led the authors to propose a clonal origin for these isolates, which would have dispersed rapidly around the world through the interchange of infected lupin seeds. Talhinhas et al. (2002) also reported a very low genetic diversity among Colletotrichum isolates causing anthracnose in different countries. The global low variation in the pathogen contrasts with the high diversity among isolates present in southern Chile. Although there is a recognizable group that encompasses most of the local isolates (17 out of 19), this group includes 12 different haplotypes and, overall, 14 molecular phenotypes were present. Furthermore, the broad virulence spectrum that was detected argues for the existence of different strains. Even after extensive studies carried out on C. lupini, the teleomorph Glomerella has never been found in Europe, where introduction of this phytopathogen is assumed (Nirenberg et al., 2002). The absence of the teleomorph would explain the low diversity reported among isolates (Yang \& Sweetingham, 1998; Nirenberg et al., 2002). Similarly, the teleomorph of this species has not been observed in South America, supposedly the origin of C. lupini. Thus, it has been stated that the species would not produce the perfect phase (Nirenberg et al., 2002). The high genetic diversity that we identified in the isolates from a small geographic area in Chile supports the theory of a South American origin of this phytopathogen.

According to our findings, the same fungus haplotype can infect different lupin cultivars independent of their alkaloid content, confirming earlier reports that anthracnose is completely tolerant to the presence of alkaloids without virulence differences on bitter and sweet isogenic lines of lupins (Huyghe, 1997). Furthermore, some of the same fungus haplotypes attacked different species of the genus Lupinus, a finding that is not unexpected since it is known that species of the genus Colletotrichum have a wide host range (Adaskaveg \& Harting, 1997; Yang \& Sweetingham, 1998; Sreenivasaprasad \& Talhinhas, 2005). In this study, different haplotypes infecting cultivated lupins are genetically similar to the isolate A-14 obtained from $L$. polyphyllus. Yang \& Sweetingham (1998) also isolated $C$. lupini from $L$. arboreus. These findings would indicate that 
L. polyphyllus, a perennial species present both in gardens and in a wild form, and L. arboreus, a wild species of wide distribution, constitute a native source of inoculum and variability of the fungus, where the presence of the sexual stage will not be ruled out. Future studies will be required to identify the strains that affect this host and their role in secondary infections of lupin cultivars. Theoretically, if other host options do not exist and only inoculum-free lupin seeds are planted, it would be possible to control this disease (Cowling et al., 1998).

Since the 1990s, the major challenge in lupin improvement has been increasing anthracnose resistance (Cowling et al., 1998). Inoculation assays to detect anthracnose-tolerant genotypes have only utilized one strain of $C$. lupini because low pathogen diversity was assumed (Yang et al., 2004; Feiler \& Nirenberg, 2004). However, this approach does not contribute to a durable tolerance of the cultivars when you consider the existence of diverse haplotypes of $C$. lupini. Pecosa-Baer, a cultivar selected in Chile under natural conditions with high anthracnose pressure (von Baer et al., 2009), has a good tolerance for most tested isolates. This cultivar is derived from TypTopBaer, one of the most tolerant cultivars tested by Feiler \& Nirenberg (2004). However, if Pecosa-Baer is inoculated with isolate A-7, up to $35 \%$ of seedlings are affected. Recently, it has been shown that anthracnose resistance in lupin cultivars is temperature dependent (Thomas et al., 2008). This environmental factor can also affect the virulence of different $C$. lupini strains. It is obvious that at least in Chile, no single isolate will suffice for resistance screening. The genetic diversity and variability in virulence identified among isolates through this work could be exploited to develop breeding methods that better detect effective, more durable resistance.

\section{ACKNOWLEDGEMENTS}

Technical assistance from Rocío Ibáñez and Mónica Almarza was greatly appreciated. Thanks are due to Helgard Nirenberg from the Federal Biological Research Center for Agriculture and Forestry (Berlin, Germany) for supplying the reference isolates.

\section{REFERENCES}

Abang MM, Winter S, Green KR, Hoffman P, Mignouna HD, Wolf GA (2002) Molecular identification of Colletotrichum gloeosporioides causing yam anthracnose in Nigeria. Plant Pathology 51:63-71.

Adaskaveg JE, Hartin RJ (1997) Characterization of Colletotrichum isolates causing anthracnose of almond and peach in California. Phytopathology 87:979-987.

Afanador-Kafuri L, Minz D, Maymon M, Freeman S. (2003) Characterization of Colletotrichum isolates from tamarillo, passiflora, and mango in Colombia and identification of a unique species from the genus. Phytopathology 93:579-587.

Cowling WA, Huyghe C, Swiecicki W (1998) Lupin breeding. In: Gladstones JS, Atkins C, Hamblin J. (Eds.) Lupins as crop plants: biology, production and utilization. Wallingford. CAB International. pp. 93-120.

Feiler U, Nirenberg HI (2004) Anthracnose of lupins. Part 2: Development of infection, spread of the pathogen and survival of different varieties of Lupinus albus, L. angustifolius and $L$. luteus after infection with Colletotrichum lupini var. setosum. Nachrichtenbatt Deutscher Pflanzenschutzdienst 56:273-280.

Felsenstein J (1989) PHYLIP: Phylogeny Inference Package. Cladistics 5:164-166.

Goodwin S, Drenth A, Fry W. (1992) Cloning and genetic analyses of two higly polymorphic, moderately repetitive nuclear DNAs from Phytophtora infestans. Current Genetics 22:107-115.

Gunnell PS, Gubler WD (1992) Taxonomy and morphology of Colletotrichum species pathogenic to strawberry. Mycologia 84:157-165.

Huyghe C (1997) White lupin (Lupinus albus L.). Field Crop Research 53:147-160.

Kelemu S, Skinner D, Badel J, Moreno C, Rodriguez M (1999) Genetic diversity in South American Colletotrichum gloeosporioides isolates from Stylosanthes guianensis, a tropical forage legume. European Journal of Plant Pathology 105:261272.

Kuramae-Izioka EE, Lopes CR, Souza NL, Machado MA (1997) Morphological and molecular characterization of Colletotrichum spp. from citrus orchards affected by postbloom fruit drop in Brazil. European Journal of Plant Pathology 103:323-329.

Lotter HC, Berger DK (2005) Anthracnose of lupins in South Africa is caused by Colletotrichum lupini var. setosum. Australasian Plant Pathology 34:385-392.

Martínez-Culebras PV, Barrio E, García MD, Querol A (2000) Identification of Colletotrichum species responsible for anthracnose of strawberry based on the internal transcribed spacers of the ribosomal region. FEMS Microbiology Letters 189:97-101.

Martinez-Culebras PV, Barrio E, Suarez-Fernandez MB, GarciaLopez MD, Querol A (2002) RAPD analysis of Colletotrichum species isolated from strawberry and the design of specific primers for the identification of C-fragariae. Journal of Phytopathology 150:680-686.

Muñoz JAG, Suárez MB, Grondona I, Monte E, Buddie AG, Bridge PD, Cannon PF (2000) A physiological and biochemical approach to the systematics of Colletotrichum species pathogenic to strawberry. Mycologia 92:488-498.

Nei M (1973) Analysis of gene diversity in subdivided populations. Proceedings of the National Academy of Sciences of the USA 70:3321-3323.

Nei M, Li WH (1979) Mathematical model for studying genetic variation in terms of restriction endonucleases. Proceedings of the National Academy of Sciences of the USA 76:5269-5273.

Nirenberg HI, Feiler U, Hagedorn G (2002) Description of Colletotrichum lupini comb. nov. in modern terms. Mycologia 94: 307-320.

Peredo HL, Valenzuela FE (1988) New records of pathogenic fungi of forest plants in Chile. Boletin Micologico 3:249-52. 
Sreenivasaprasad S, Talhinhas P (2005) Genotypic and phenotypic diversity in Colletotrichum acutatum, a cosmopolitan pathogen causing anthracnose on a wide range of hosts. Molecular Plant Pathology 6:361-378.

Sweetingham MW, Cowling WA, Buirchell BJ, Brown AGP, Shivas RG (1995) Anthracnose of lupins in western Australia. Australasian Plant Pathology 24:271.

Talhinhas P, Sreenivasaprasad S, Neves-Martins J, Oliveira H (2002) Genetic and molecular characterization of Colletotrichum acutatum causing anthracnose of lupins. Phytopathology 92:986996.

Thomas GJ, Sweetingham MW, Yang HA, Speijers J (2008) Effect of temperature on growth of Colletotrichum lupini and on anthracnose infection and resistance in lupins. Australasian Plant Pathology 37:35-39.

Tivoli B, Baranger A, Avila CM, Banniza S, Barbetti M, Chen W, Davidson J, Lindeck K, Kharrat M, Rubiales D, Sadiki M, Sillero JC, Sweetingham M, Muehlbauer FJ (2006) Screening techniques and sources of resistance to foliar diseases caused by major necrotrophic fungi in grain legumes. Euphytica 147:223-253.

von Baer E, von Baer I and Riegel R (2009) Pecosa-Baer: A new cultivar of white lupin with determined bushy growth habit, sweet grain and high protein content. Chilean Journal of Agricultural Research 69:577-580.

Weimer JL (1943) Anthracnose of lupines. Phytopathology 33:249-252.

White TJ, Bruns T, Lee S, Taylor J (1990) Amplification and direct sequencing of fungi ribosomal RNA genes for phylogenetics.
In: Innis MA, Gelfand DH, Sninsky JJ, White TJ. (Eds.) PCR protocols. A Guide to Methods and Applications. San Diego CA. Academic Press. pp. 315-322.

Williams JGK, Kubelik AR, Livak KJ, Rafalski JA, Tingey SV (1990) DNA polymorphisms amplified by arbitrary primers are useful as genetic markers. Nucleic Acids Research 18:65316535.

Yang HA, Sweetingham MW (1998) The taxonomy of Colletotrichum isolates associated with lupin anthracnose. Australian Journal of Agricultural Research 49:1213-1223.

Yang HA, Boersma JG, You M, Buirchell BJ, Sweetingham MW (2004) Development and implementation of a sequence-specific PCR marker linked to a gene conferring resistance to anthracnose disease in narrow-leafed lupin (Lupinus angustifolius L.). Molecular Breeding 14:145-151.

Yang H, Renshaw D, Thomas G, Buirchell B, Sweetingham M (2008) A strategy to develop molecular markers applicable to a wide range of croses for marker assited selection in plant breeding: a case of study on anthracnose disease resistance in lupin (Lupinus angustifolius L.). Molecular Breeding 21:473-483.

Yap IV, Nelson RJ (1996) Winboot: a Program for Performing Bootstrap Analysis of Binary Data to Determine the Confidence of UPGMA-based Dendrograms. Manila, Philippines, IRRI.

Yeh FC, Boyle TJB (1999) Popgene version 1.31. Microsoft window-based freeware for population analysis. Edmonton, Canada. University of Alberta and Centre for International Forestry Research.

Zar JH (1999). Biostatistical Analysis. Englewood Cliffs NJ. Prentice Hall Internacional Inc.

TPP 8140 - Received 10 November 2008 - Accepted 21 May 2010

Section Editor: Gary Odvody 